Illinois State University

ISU ReD: Research and eData

Theses and Dissertations

5-26-2019

\title{
The Association Between Attachment And Conflict Resolution During Friendship Conflict Among College Students
}

\author{
Alison Hamlet \\ Illinois State University, ali.nicole7777@gmail.com
}

Follow this and additional works at: https://ir.library.illinoisstate.edu/etd

Part of the Clinical Psychology Commons

\section{Recommended Citation}

Hamlet, Alison, "The Association Between Attachment And Conflict Resolution During Friendship Conflict Among College Students" (2019). Theses and Dissertations. 1137.

https://ir.library.illinoisstate.edu/etd/1137

This Thesis is brought to you for free and open access by ISU ReD: Research and eData. It has been accepted for inclusion in Theses and Dissertations by an authorized administrator of ISU ReD: Research and eData. For more information, please contact ISUReD@ilstu.edu. 


\title{
THE ASSOCIATION BETWEEN ATTACHMENT AND CONFLICT RESOLUTION DURING FRIENDSHIP CONFLICT AMONG COLLEGE STUDENTS
}

\begin{abstract}
Alison Hamlet
54 Pages

This study is about college students' attachment to friends and how conflict resolution is related attachment anxiety and attachment avoidance. Studies have found low attachment anxiety and low attachment avoidance to be related to effective coping strategies and to the compromising conflict resolution style. Many studies have focused on how participants generally resolve conflict. The current study is focused on how participants have actually resolved conflict and how they believe they would resolve conflict in a hypothetical situation. Participants were asked if they could think of a conflict with a friend in the past 6 months and if they answered yes then they wrote about the conflict, but if they answered no then they read a hypothetical conflict. Participants completed an attachment measure, a conflict resolution measure, and rated how severe their experience of the conflict was. Attachment anxiety was positively related to the obliging and compromising conflict resolution styles, and attachment avoidance was positively related to the avoiding conflict resolution style in the real-life conflict subsample. Attachment anxiety was positively related to the obliging and avoiding conflict resolution styles, and attachment avoidance was positively related to the avoiding conflict resolution style in the hypothetical-conflict subsample. People high in attachment anxiety are likely to please their friend for fear the friend would leave them. People high in attachment avoidance are likely to withdraw from conflict.
\end{abstract}


KEYWORDS: attachment, conflict resolution, friendships, relationship conflict, college students 


\title{
THE ASSOCIATION BETWEEN ATTACHMENT AND CONFLICT RESOLUTION DURING FRIENDSHIP CONFLICT AMONG COLLEGE STUDENTS
}

\author{
ALISON HAMLET
}

\author{
A Thesis Submitted in Partial \\ Fulfillment of the Requirements \\ for the Degree of \\ MASTER OF SCIENCE \\ Department of Psychology \\ ILLINOIS STATE UNIVERSITY
}


Copyright 2019 Alison Hamlet 


\title{
THE ASSOCIATION BETWEEN ATTACHMENT AND CONFLICT RESOLUTION DURING FRIENDSHIP CONFLICT AMONG COLLEGE STUDENTS
}

\author{
ALISON HAMLET
}

COMMITTEE MEMBERS:

Jeffrey Kahn, Chair

Susan Sprecher 


\section{ACKNOWLEDGMENTS}

I would like to take a moment to appreciate my grandparents, especially my Granny, for always pushing me to be and do the best I possibly can and supporting me through everything. My Granny held me to the highest standards and helped me stay true to who I am. My Nana remained a source of light and gave me hope.

I thank both my mother and dad for always believing, even assuming, I can and celebrating my accomplishments even when I don't. I value your forms of celebrating, including telling everyone you know about my successes.

To my friends and fiancé, I express gratitude for sticking by me when I didn't have time or energy but loving me anyway. I specifically thank you for forcing me to be social and relax, plus getting me a companion for home.

Finally, I would like to state how much I value my thesis chair, Dr. Jef Kahn, who has been a priceless mentor throughout my time at Illinois State University. I count myself blessed to have a mentor with endless patience and encouragement.

A.H. 
Page

ACKNOWLEDGMENTS

$\begin{array}{ll}\text { CONTENTS } & \text { ii }\end{array}$

TABLES

FIGURES

CHAPTER I: STATEMENT OF THE PROBLEM 1

CHAPTER II: REVIEW OF THE LITERATURE

$\begin{array}{ll}\text { Friendships } & 5\end{array}$

Relationship Conflict $\quad 9$

$\begin{array}{ll}\text { Attachment } & 12\end{array}$

$\begin{array}{ll}\text { Attachment Formation and Styles } & 12\end{array}$

$\begin{array}{ll}\text { Adult Attachment } & 14\end{array}$

Attachment and Conflict Resolution $\quad 18$

$\begin{array}{ll}\text { The Present Study } & 22\end{array}$

$\begin{array}{ll}\text { CHAPTER III: METHOD } & 25\end{array}$

$\begin{array}{ll}\text { Participants } & 25\end{array}$

$\begin{array}{ll}\text { Instruments } & 26\end{array}$

$\begin{array}{ll}\text { Attachment } & 26\end{array}$

Severity of the Conflict $\quad 26$

$\begin{array}{ll}\text { Conflict Resolution } & 27\end{array}$

$\begin{array}{ll}\text { Procedure } & 27\end{array}$

Plan for Data Analysis $\quad 29$

CHAPTER IV: RESULTS 30 
Real-Life Conflict Subsample

Hypothetical-Conflict Subsample

CHAPTER V: DISCUSSION

Discussion of Results

Limitations and Future Directions

Implications

REFERENCES 


\title{
TABLES
}

Table

Page

1. Means and Standard Deviations of Measures Concerning Real-Life Conflict

2. Correlations from Measures Concerning Real-Life Conflict

3. Moderation of Severity Ratings on Attachment Anxiety and Avoidance with Conflict

\author{
Resolution Styles

4. Means and Standard Deviations of Measures Concerning Hypothetical Conflict

5. Correlations from Measures Concerning Hypothetical Conflict 


\section{FIGURES}

Figure $\quad$ Page

1. Five ways of resolving conflict based on concern for self versus concern for others 11

2. Model of Self (Dependence) vs. Model of Others (Avoidance) 16

3. Moderation effect of conflict severity on the association between attachment avoidance and dominating conflict-resolution style 


\section{CHAPTER I: STATEMENT OF THE PROBLEM}

Friendships play a critical role in the lives of young adults. Tillmann-Healy (2003) gave a "close friend" definition as "somebody to talk to, to depend on and rely on for help, support, and caring, and to have fun and enjoy doing things with" (p. 730). Friendships are also characterized by words such as voluntary, intimate, trust, respect, commitment, generosity, loyalty, and acceptance (Rybak \& McAndrew, 2006). Though friendships are not defined by formal rules, there are unwritten expectations, such as helping when in need, keeping secrets in confidence, being emotionally supportive, mutual respect and trust, and commitment to the friendship (Argyle \& Henderson, 1984; Fuhrman, Flannagan, \& Matamoros, 2009; Hojjat \& Moyer, 2017).

Oftentimes, a friend is not defined by the frequency of in-person interactions (Rybak \& McAndrew, 2006) but by the nature of those interactions. For example, giving support during times of coping with personal conflict is one of many functions of friends (Tokuno, 1983).

Friends also give advice, listen with sympathy and empathy, offer acceptance and reassurance, play a role in merging and separating romantic relationships, give opportunities for identity resources such as the self-concept, and provide a place to belong (Buote et al., 2007; Perlman, Stevens, \& Carcedo, 2015; Tokuno, 1983).

Given these beneficial functions, friendships are particularly important for new college students. Entering college can be a very stressful time for emerging adults. Emerging adults need to learn how to live an independent life, be in charge of their own finances, make new friends, and keep up with schoolwork (Brougham, Zail, Mendoza, \& Miller, 2009). Oswald and Clark (2003) conducted a study focusing on high school best friendships and the first year of college and found within the first year of college was a time when high school best friends turned into close or casual friendships, with participants reporting fewer rewards and investments 
concerning their high school best friendships (Oswald \& Clark, 2003). New friendships in college frequently form in triads in the first few months by developing friends through other friends (Perlman et al., 2015). During a stressful transition such as college, friends help with coping, though friendships wane during the first year of a student's university experience if the student moves to a new area versus living at home and commuting (Buote et al., 2007). Being able to continue friendships through transitions such as college can assist with the stress of the transition (Rybak \& McAndrew, 2006).

Unfortunately, friendships are occasionally marked with conflict, which can include verbal disagreements as well as physical altercations (Salvas et al., 2014). As Hojjat and Moyer (2017) stated, "friendships constitute one of the most common contexts...people encounter transgressions, provocations, betrayals, and related aversive experiences" (p. 196). Conflict occurs when people have opposing views and include emotional expression (Salvas et al., 2014). Conflict within friendships, to a certain point, is beneficial due to prompting social adjustment, change, a higher quality friendship, emotional sensitivity, emotional perspective understanding, and practice of interpersonal skills (Salvas et al., 2014). Conflict management has been shown to be more effective in best friendships compared to acquaintances (Perlman et al., 2015). Yet it is also the case that increased conflict within friendships may promote aggressive or manipulative conflict resolution strategies (Salvas et al., 2014), sometimes ending friendships (Perlman et al., 2015). Additionally, breaking the unwritten expectations within a friendship is one of the most common reasons friendships end (Argyle \& Henderson, 1983; Hojjat \& Moyer, 2017).

Examining how college students resolve conflict within the context of friendships is therefore an important research goal. People initially learn conflict resolution strategies from family conflict in childhood via modeling (Herrera \& Dunn, 1997). The conflict resolution 
strategies endorsed by parents and siblings when in conflict with a child then influence the conflict resolution strategies the child employs in future conflict instances (Herrera \& Dunn, 1997). Conflict between parents and children naturally increases during adolescence and is normal and adaptive in learning negotiation when not in excess (Ehrlich, Dykas, \& Cassidy, 2012). Nevertheless, adolescents experiencing high levels of conflict in family and friendships are more likely to suffer from lower social functioning and antisocial behavior (Ehrlich et al., 2012).

In addition to modeling, another potential mechanism for how one's family experiences affect one's conflict resolution strategies in later adult friendship is attachment. The attachment style that children develop during infancy and childhood, usually within the family, influences their future behavior, emotion, and cognition. Attachment orientation influences the child's future relationships by creating an internal working model of how relationships work and what to expect from them. Friendships are formed using this internal working model of relationships (Heinze, Cook, Wood, Dumadag, \& Zimmermann, 2018). Many researchers measure attachment across relationships whereas some studies measure attachment in relationship-specific contexts (Fraley, Hudson, Heffernan, \& Segal, 2015). Support has been found for a significant correlation between friendship and parental attachment in adolescence (Gorrese \& Ruggieri, 2012) such that adolescents who had a secure attachment with their parents were likely to have secure attachment with their friends. Such attachment security is beneficial because those with a secure attachment with their friends use their friends as a secure base to form new securely attached friendships, to explore the world, and to develop adaptive emotion regulation skills (Heinze et al., 2018). Adolescents begin using friends as a safe haven, or a place to go when distressed (Fraley \& Davis, 1997), which is partly why adolescents begin shifting time from parents to their friends 
(Rosenthal \& Kobak, 2010). Further, those with securely attached friendships are less likely to have negative mental health issues (Heinze et al., 2018).

The purpose of the current study was to examine the association between college students' attachment style and their conflict-resolution strategies in friendships. Specifically, do attachment anxiety and avoidance have a relationship with the strategies employed when it comes to resolving a conflict or disagreement with a friend? Friendships and romantic relationships have been found to be dissimilar in terms of attachment style and the role one's style plays in how an individual resolves conflict. For instance, common conflicts in adolescent friendships revolve around personality and standards of friendship, whereas common conflicts in adult romantic relationships are relational rules and norms and specific behaviors that upset one partner (Canary, Cupach, \& Messman, 1995).

The current study adds to the field of friendships and the conflict resolution strategies as they relate to attachment style. Romantic relationships have been commonly studied with respect to attachment and conflict resolution. In the next chapter I review studies on attachment and conflict resolution within romantic relationships. As previously stated, however, attachment plays a different role in friendships than it does in romantic relationships (Bippus \& Rollin, 2003). Further, most of the existing research (to be reviewed) had participants respond about conflict resolution according to how they generally respond while in conflict with their romantic partner, whereas the current study had participants respond about conflict resolution according to both how they responded in a past situation or how they would respond in a vignette. Thus, this study makes a unique contribution to the literature on relationships and conflict resolution by examining attachment in friendship and conflict resolution according to a specific conflict situation instead of how one generally resolves conflict. 


\section{CHAPTER II: REVIEW OF THE LITERATURE}

\section{Friendships}

For preschool-age children, a friend is someone with whom they play. Parents are able to identify their child's preschool best friend, and preschoolers who are more responsive and reciprocal are more likely to have friends (Sebanc et al., 2007). Children with their friends act more positively engaged, as well as smile, converse, disclose, and help more than with nonfriends. With time, friends become more alike one another (Hojjat \& Moyer, 2017). Close friendships that begin in kindergarten tend to last about two years compared to other friendships. Children generally consider all friends equal, not labeling some as friends and others as best friends until around the second and third grades (Sebanc et al., 2007). Around the age of 6, the need for acceptance arises (Hojjat \& Moyer, 2017). Sebanc et al. (2007) found that peer acceptance positively predicted having a friend and a best friend in 3- to 7-year-old children, that prosocial behavior in 3- to 7-year-old children predicted having a best friend, and peer acceptance was related to prosocial behavior, such as sharing toys (Sebanc et al., 2007).

Around the age of 8 to 10 years, within the preadolescence years, children develop their first close friendship where the child learns to think outside of themselves and instead think about what would benefit another person; they wonder, "what should I do to contribute to the happiness...of my chum" (Berndt, 2004, p. 208). Typical friend activities include playing games, talking, completing schoolwork, and going to the movies together (Berndt, 2004). During this preadolescent age, the need for intimacy is developed (Hojjat \& Moyer, 2017), and this intimacy occurs within this close friendship. Intimacy is where two people relay the other's worth through validation and modify their own behavior to meet the needs of the other (Berndt, 2004). Intimacy 
may also include divulging personal and sometimes private information about oneself, occasionally consisting of one's feelings and thoughts.

Close friends tend to become more necessary than parents for social support during adolescence (Hojjat \& Moyer, 2017). Adolescents tend to mention self-disclosure to describe their intimacy within friendships more frequently than elementary-aged children. Development of this close friendship aids in the child's awareness of another's needs and desires as well as learning to put effort into filling those needs and desires for another. Friends also influence attitudes, behaviors, adjustment, and development in various areas such as drug and alcohol use, school, and success within school (Berndt, 2004). Further, when same-sex friends are developed, understanding of the experience of sharing the same sex is shared; opposite-sex friends have an advantage by gaining insight into how members of the other sex think, feel, and act (Hojjat \& Moyer, 2017).

Children who do not develop friends during the elementary school years are more likely to have symptoms of depression, anxiety, and social withdrawal (Berndt, 2004) and are vulnerable to other aspects of socioemotional adjustment such as loneliness, self-esteem, and coping with peer victimization. Children who experience peer rejection instead of peer acceptance report the highest loneliness; loneliness is predicted by the quantity and quality of friendships during middle childhood (Hojjat \& Moyer, 2017). Lower quality of friendship is also related to depressive symptoms in children. Depressive symptoms in junior-high age adolescents were found to predict an increase of negative qualities and a decrease of positive qualities in friendships. Anxiety is related to friendship difficulties, including friendship quality. Over time, more anxiety is a predictor of lower quality friendships (Hojjat \& Moyer, 2017). Children with a genetic disposition for anxiety are likely to have friends who experience anxiety, which is linked 
to more anxiety symptoms (Hojjat \& Moyer, 2017). Concerning self-esteem in middle childhood, two major predictors are peer acceptance and friendship; in adolescence, friendship is the stronger predictor of self-esteem. In adolescence, when friendships become more important, friendship intimacy was most highly and positively linked to self-esteem than in preadolescence (Hojjat \& Moyer, 2017).

The functions of friends change only slightly throughout the life span (Hojjat \& Moyer, 2017). Friendships in childhood are centered on play, whereas friendships in adolescence tend to replace parents with respect to whom the adolescents spend time with, trust, and meet attachment needs (Fraley \& Davis, 1997; Hojjat \& Moyer, 2017). These adolescent friendships also serve as a precursor for adolescents' romantic relationships. Friendships are found to be most abundant and emphasized in adolescence and young adulthood compared to other periods of time (Hojjat \& Moyer, 2017). In young and middle adulthood, although romantic partners increase in importance, friends remain significant for leisure-time activities, trusting with information, receiving validation and emotional support, and as an attachment figure (Hojjat \& Moyer, 2017). In this way, friendships continue their functions from adolescence to young and middle adulthood, including the essential dimensions of emotional closeness and exchange of support. Young adults often have large social networks, and one reason for this is being introduced to new places and activities, such as college or work. One of three patterns of social networks generally develops over time: a person may have (a) only family relationships and no friendships, (b) many friendships and identified friends who are closer and those who are acquaintances, or (c) a small number of close friends (Hojjat \& Moyer, 2017).

A dimension thought to be fundamental to friendship among young adults is emotional closeness (Hojjat \& Moyer, 2017). Emotional closeness is often related to how similar two 
friends are concerning their values and individual characteristics. People tend to be attracted to others who are like them to confirm their views about oneself and the world, according to the similarity-attraction theory (Hojjat \& Moyer, 2017). Therefore, two people who share similar self- and worldviews are likely to find interactions enjoyable and, with several enjoyable interactions, the two people begin to feel close to one another (Hojjat \& Moyer, 2017). Another valuable dimension of friendship is the exchange of support, where friends attempt to support each other equally long-term (Hojjat \& Moyer, 2017). A best friend is more exclusive, is characterized by greater companionship compared to other friendships (Sebanc, Kearns, Hernandez, \& Galvin, 2007), involves more support, and is more stable than close friendships or acquaintances (Perlman et al., 2015).

As would be expected given the qualities of friendships (e.g., voluntary companionship; Perlman et al., 2015), social support from friends has been linked to psychological well-being as well as self-esteem and self-worth (Buote et al., 2007). In a friendship, chances to help other friends are present (Buote et al., 2007), and friends are a major contributor of happiness. Researchers theorize that the more knowledge shared between friends, the greater empathy and sensitivity (Rybak \& McAndrew, 2006). Friendship quality is positively correlated with psychological well-being and negatively correlated with internalizing problem behaviors and externalizing problem behaviors (Pittman \& Richmond, 2008).

In young adulthood, trust and emotional closeness are built through regular positive and intimate interactions with acquaintances, with personal information being shared. This process is how acquaintances become friends. Young adults in college perceive friendships as more supportive when friendships are more securely attached (as discussed in depth later on). Friendships are also more valuable to single adults to fulfill emotional needs and support 
compared to adults who are married or have children. In contrast, among adults who are married or have children, emotional needs and support are often fulfilled by the spouse and children than by friends (Hojjat \& Moyer, 2017).

Overall, friendships provide many needs throughout life. Friends provide companionship, a reliable alliance, nurturance, affection, intimacy, acceptance, validation, empathy, and social support. Friends are typically prioritized over parents in adolescence. Emerging adults turn to their friends during stressful times, such as moving away to college. With the transition to college, many opportunities to make friends are present through the new environments such as classes and clubs (Hojjat \& Moyer, 2017). According to Buote et al. (2007) "it is probable that a best friend may be one of the most important assets in major life transitions" (Buote et al., 2007, p. 666).

\section{Relationship Conflict}

Conflict between people is frequently described as a difference of opinions and motivations, often filled with emotion (Ben-Ari \& Hirshberg, 2009; Hartup et al., 1988; Johnson \& Johnson, 1996; Shantz, 1987). When conflict arises in preschool-age children, the child is more likely to resolve the conflict in a fair manner when it concerns friends versus children who are not friends (Sebanc et al., 2007). Children are more likely to resolve conflict with their friends by negotiating and using other tactics to preserve the relationship (Hojjat \& Moyer, 2017). Conflict between adolescent friends center around trust or intimacy being broken (Laursen, 1995). Laursen (1995) found adolescent participants had on average one conflict with their friend each day, and girls had a higher trend of conflict than boys, specifically, girls reported 1.50 conflicts each day and boys reported 0.87 conflicts each day with friends. Adolescent participants reported having conflict with close friends most often about friendship 
issues, heterosexuality, standards of behavior, behavior and criticism, teasing, put-downs, and differences of idea or opinion (Laursen, 1995). Friends may also have conflicting goals, which may lead to conflict (Lewis, Al-Shawaf, Russell, \& Buss, 2015). The disagreement could move from a verbal dispute to a physical dispute with the help of emotions being expressed. Scholars believe that disagreements are normal and essential to relationships but that they also add to one's growth and adaptation. Erikson (1980) and Piaget (1932) both viewed conflict to be a major source of learning and development for the growing person; conflict can aid in an adolescent's developing identity (Ben-Ari \& Hirshberg, 2009).

The way someone resolves conflict is developed in childhood and influences their future conflict resolution tactics (Herrera \& Dunn, 1997). These tactics are not random; they can be organized in a taxonomy. Rahim (1983) theorized that two dimensions of addressing conflict exist, and these two dimensions further split into five specific ways of resolving conflict. The two primary dimensions are (a) concern for self and (b) concern for others. The authors viewed concern for self as defending one's own needs and interests, whereas concern for others was putting the other person's needs and interests first to cooperate with them (Rahim, 1983).

According to Rahim (1983), the five specific ways of resolving conflict are compromising, integrating, obliging, dominating, and avoiding. The measurement of these five styles was developed through repeated feedback from Master of Business Administration and undergraduate students and managers. The items in the measurement were then rated on a 5point Likert scale by participants, where higher numbers meant higher use, and the participants rated the items on clarity, consistency, and ambiguity. The researchers took the responses and revised them as necessary to develop the measure, conducting a factor analysis afterwards. Compromising is theorized to be the center of the five (see Figure 1), with equal concern for self 
and others and the goal is being understanding, flexible, and coming to a solution that works for both parties. Integrating is having high concern for both self and for others, and the goal is for both parties to have the maximum benefit and a way where both get what they desire. Obliging is having a high concern for others and low concern for self; usually conflicts bring about anxiety and are therefore oriented at having harmony in the relationship. The obliging person desires to remain in the other's good graces. Dominating is having high concern for self and low concern for others; the person seeks what is best for their own needs and is stubborn towards compromising. Lastly, avoiding is having low concern for both self and others. The avoiding person sees no benefit in establishing a solution and chooses instead to withdraw, which prevents any sort of solution from being reached (Ben-Ari \& Hirshberg, 2009). Figure 1, which was adapted from Rahim (1983), is an illustration of the five conflict styles by the dimensions of concern for oneself versus concern for others.

Concern for Self

High Low

\begin{tabular}{|c|c|c|c|}
\hline $\begin{array}{l}\text { Concern } \\
\text { for }\end{array}$ & High & Integrating & Obliging \\
\hline Others & Low & Dominating & Avoiding \\
\hline
\end{tabular}

Figure 1 Five ways of resolving conflict based on concern for self versus concern for others.

An alternative view of conflict was presented by Rusbult, Zembrodt, and Gunn (1982), who identified four responses people take when they are dissatisfied in a relationship: exit, 
loyalty, voice, and neglect. Exit is defined as when a person leaves the relationship, such as transforming from romantically involved to just being friends. Loyalty is the response characterized by waiting out the dissatisfaction and hoping for the relationship to become better. The response of voice is described as actions people take to talk about the problem and actively put effort to change the issue, such as problem-solving or seeking a therapist's perspective about the issue. Neglect responses can be when a person allows the problem to persist, ignores their significant other, avoids discussion of the issue, or begins an affair instead of addressing their dissatisfaction. The authors theorized the four responses to be on two dimensions: constructive versus destructive and active versus passive. Constructive and destructive responses are meant to either maintain or destroy the relationship. Loyalty and voice are constructive responses since they are responses to keep the relationship alive whereas exit and neglect are responses that generally destroy the relationship.

Rahim (1983) and Rusbult et al. (1982) both theorized ways to respond to relationship conflict. The current study will use the Rahim (1983) conceptualization of conflict resolution behaviors as they relate to friendship conflict. The Rahim (1983) framework has more empirical support and can be adapted for use in research on friendship conflict.

\section{Attachment}

The ways in which people cope and resolve interpersonal conflict are associated with their early childhood interpersonal experiences. In particular, one's attachment style has an effect on how one responds during an interpersonal dispute.

\section{Attachment Formation and Styles}

Infants automatically create an attachment with their caregiver (Ben-Ari \& Hirshberg, 2009). An infant's survival relies on their ability to appeal to an attachment figure's attention and 
to keep in close proximity to the attachment figure, also known as the attachment behavioral system (Fraley \& Shaver, 2008). Bowlby theorized that people create attachments to their caregivers through internal models of oneself and of others, each of which can be viewed in a positive or negative light (Bowlby, 1973). The attachment figure would be someone who had provided support or cared for the infant previously (Fraley \& Shaver, 2008). The internal working model is meant to shape what and how a person perceives new experiences and how the person encodes new information (Bartholomew \& Horowitz, 1991).

When the infant is in danger, the infant learns to rely on their attachment figure, parent or guardian, to feel safe with them (Bartholomew \& Horowitz, 1991). When separated, the infant displays attachment behaviors, such as crying and searching. The attachment behavioral system keeps track of where the attachment figure is and if the attachment figure is accessible. When the infant feels confident about the attachment figure being accessible, the infant feels loved, whereas when the infant feels the attachment figure is inattentive and inaccessible, the infant feels anxiety and displays additional attachment behaviors. The attachment behaviors persist until the child becomes exhausted or the child is responded to and feels content about their proximity to their attachment figure. The infant's behavior to seek proximity to their attachment figure is the infant searching for their safe haven, whereas when the child feels content about their attachment figure's location, the child uses their attachment figure's location as a secure base (Fraley \& Shaver, 2008).

Ainsworth studied infant attachment through what she termed the "Strange Situation," where the parent and infant are in a playroom together. A stranger comes in, and then the parent leaves the room. The child's reactions to the parent's disappearance and then to the parent's reappearance are reflections of the attachment style (Ainsworth, Blehar, Waters, \& Wall, 1978). 
The infants then use what they learn from this attachment relationship to have social interactions and create future relationships (Ben-Ari \& Hirshberg, 2009).

The two aspects that create the infant's attachment style are the infant's view of their attachment figure's ability to provide support and protection to the infant and the infant's judgment of their worth to be provided with assistance (Bartholomew \& Horowitz, 1991). Mary Ainsworth proposed three styles of attachment from her strange-situation procedure: secure, anxious/avoidant, and anxious/ambivalent. Secure infants were likely to use their mothers as a secure base to feel comfortable to explore when the mother was present and sought to be close to their mother upon her reappearance, eliciting a positive interaction. Anxious/avoidant infants are characterized by nonchalance towards their mother's disappearance and reappearance and continuance of exploration behavior. Anxious/ambivalent infants are characterized by intense, emotional reactions when they are separated from their mothers yet ambivalence at their mother's return. When their mother returns, the infant is conflicted with the desire to be close and the desire to be angry and avoid her, which is displayed through their response in being soothed by their mother (Ainsworth et al., 1978).

\section{Adult Attachment}

One's learned attachment style from infancy persists through one's life, adulthood included (Bippus \& Rollin, 2003). The only way this internal working model would change is through a strong emotional experience (Bartholomew \& Horowitz, 1991). The emotional bond between romantic partners is comparable to the emotional bond between the infant and their attachment figure; the attachment behavioral system is activated in both cases. In each case, the person feels more secure when their attachment figure is within close proximity and attentive, the person feels anxious when they feel discontent about their attachment figure's proximity or is 
inaccessible, the person is preoccupied with their attachment figure through physical connections and sharing stories, and the person receives baby talk, similar to how a mother would speak to her infant. These similarities suggest that adult relationships should have similar functions to infant-caregiver relationships, and attachment styles learned in childhood should be observable in adult relationships (Fraley \& Shaver, 2008).

Although the three-category model has been used in many attachment studies, an alternative representation of attachment is to view it as categories that vary along two dimensions. The child can vary from low to high regarding their trust for their caregiver to provide support and protection as well as their belief about their personal worth to be attended to (Ben-Ari \& Hirshberg, 2009). In this way, attachment could be broken into four styles: secure, preoccupied, fearful-avoidant, and dismissive-avoidant. Bartholomew and Horowitz (1991) described the four attachment styles along two dimensions of one's positive or negative view of oneself and view of others (see Figure 2). One's view of self is a set of beliefs about how worthy one is for others to respond in a positive manner (Griffin \& Bartholomew, 1994). The degree of anxiety and dependence one feels in interpersonal relationships is connected to one's positive or negative view of self. One's view of others is a set of beliefs concerning how much one expects others to be available and supportive to oneself (Griffin \& Bartholomew, 1994). One's positive or negative view of others is connected to the degree a person avoids being close in interpersonal relationships (Griffin \& Bartholomew, 1994). 


\begin{tabular}{llll} 
View & \multicolumn{2}{c}{ View of Self (Dependence) } \\
of & & Positive (Low) & Negative (High) \\
\cline { 3 - 4 } Others & Positive (Low) & Secure & Preoccupied \\
(Avoidance) & Negative (High) & Dismissing & Fearful \\
\cline { 3 - 3 } & &
\end{tabular}

Figure 2 Model of Self (Dependence) vs. Model of Others (Avoidance).

An individual who has a secure attachment style has a positive view of others in which they are accepting and respond to oneself as well as a positive view of oneself where one is worthy of being responded to and loved (Bartholomew \& Horowitz, 1991). Characteristics of relationships for people with secure attachments are longer duration, better quality, and more intimacy when compared to other attachment styles (Bippus \& Rollin, 2003). The person with a preoccupied attachment style has a negative view of self, in which the self is unworthy of love, yet they have a positive view of others, making the person desire to be accepted by others whom they value and to take personal blame when rejected by others. Due to this need for others' acceptance, preoccupied-style persons are open to establishing relationships. People with the fearful-avoidant attachment style have a negative view of both self and others, where the self is unworthy to be loved, and others are not to be trusted. This type of person evades being emotionally close with others and expects to be rejected by other people. The person with a dismissive-avoidant style is characterized by the view that the self is worthy to be loved while others are perceived negatively and are prone to disappoint the self. Self-worth continues through rejection by others by minimizing the rejection (Bartholomew \& Horowitz, 1991). Self-reliance is a strong characteristic of the dismissive-avoidant style (Bippus \& Rollin, 2003). People with 
this style also evade emotionally close relationships and keep distance from others to preserve one's independence; by intentionally straying from close relationships, the people with fearful and dismissing styles fail to alter their internal working models concerning others. The preoccupied-avoidant style is similar to the fearful-avoidant style in their need of others to provide a positive regard of them (Bartholomew \& Horowitz, 1991).

The attachment literature is divided between attachment types (i.e., secure, preoccupied, fearful, and dismissing) and attachment dimensions of anxiety and avoidance. Attachment types may leave out information in regard to one's attachment (Fraley et al., 2015); thus, the present study will focus on the two attachment dimensions. The anxiety dimension is the degree to which a person is uncomfortable in reaching out to others for closeness and worries about others rejecting them according to their view of self. A person who is low in anxiety is comfortable reaching out to others and views the self as worthy of love, whereas a person who is high in anxiety has a low view of self, feeling they are not worthy of love and worries others will reject them. The avoidance dimension is the degree to which a person believes others are unlikely to provide support and comfort to the person as well as how uncomfortable the person is in being close with and depend on others. A person low in avoidance has a positive view of others and therefore is comfortable with dependency and believe others are likely to provide support; a person high in avoidance is uncomfortable with dependency and believes that others are unlikely to provide support or comfort (Cann, Norman, Welbourne, \& Calhoun, 2008; Fraley et al., 2015). Fraley et al. (2015) measured attachment within mother, father, partner, and best friend relationships and found support for a dimensional model of attachment through demonstrating variability in attachment anxiety and avoidance as a whole and within specific relationships, demonstrating how attachment is not categorical. Anxiety and avoidance are continuous 
variables where a person may have higher or lower anxiety and avoidance in distinct relationships, such as a parent compared to friends, and are not fixed in one attachment style for each relationship (Fraley et al., 2015).

\section{Attachment and Conflict Resolution}

One's attachment style has implications for how one resolves conflict (Ben-Ari \& Hirshberg, 2009). Though a secure attachment style is ideal, a person may develop an insecure attachment style instead that is preoccupied, dismissing, or fearful (Bartholomew \& Horowitz, 1991). In general, secure attachment is associated with adaptive coping. Seiffge-Krenke (2006) found that adolescent participants with a secure style endorsed more active coping strategies and used understanding for the other's perspective concerning relationship stress with parents and peers. Adolescents with a secure style of attachment also perceived less stress in their relationship with their parents and endorsed more active coping strategies. An adult with a secure attachment is likely to use effective strategies, such as seeking social support during an emotional situation and prosocial strategies for relationship conflict. An adult who has a secure attachment and is in an emotional situation is likely to use strategies that are more effective and productive as well as put more effort into finding solutions to the issue at hand. The person with a secure attachment is also likely to seek social support during the emotional situation (Ben-Ari \& Hirshberg, 2009; Heinze et al., 2018; Mikulincer 1998; Mikulincer, Orbach, \& Iavnieli 1998). Another study found that the adult participants with a secure attachment were likely to use prosocial strategies for relationship conflict, and their friends reported greater relationship quality compared to participants with other styles (Bippus \& Rollin, 2003). The friends of the secure-attachment participants agreed with the participants about the participants' use of 
prosocial strategies. Securely attached participants were reported by their friends to use all conflict strategies besides avoiding (Bippus \& Rollin, 2003).

Bartholomew and Horowitz (1991) conducted a study with undergraduate students and their close, nonromantic friend focusing on the attachment style participants had with their friend and the ways in which participants resolved interpersonal problems with their friend. The authors found that participants who were categorized as the preoccupied style were more likely to try to solve interpersonal conflict through trying to be warm yet acting controlling. A lack of warmth during interpersonal situations was reported by those with the dismissive style. Adults with an avoidant style of attachment endorsed strategies to gain distance during an emotionally charged situation (Ben-Ari \& Hirshberg, 2009). People with fearful attachment elicited a passive response to interpersonal conflict. Seiffge-Krenke (2006) found that adolescents who had a preoccupied style of attachment perceived higher stress in their relationships with their parents, and this stress remained high throughout adolescence. Moreover, the adolescent participants with a preoccupied style were more likely to use withdrawal when dealing with peer, romantic partner, and parental stress than those with a secure attachment style (Seiffge-Krenke, 2006). How a participant rated their attachment style aligned with how their friends and family rated the participant's attachment style (Bartholomew \& Horowitz, 1991).

Ben-Ari and Hirshberg (2009) proposed a model where conflict perception mediates the relationship between attachment style and how a person copes with conflict. The researchers used the Rahim Organizational Conflict Inventory (ROCI-II; Ben-Ari \& Hirshberg, 2009). The ROCI-II was originally developed to measure conflict resolution behaviors in organizational settings with employees and employers. The participants rate the style of conflict resolution choices that are more like them from the styles of obliging, dominating, compromising, avoiding, 
and integrating. The participants' scores are then used to classify which style(s) they most frequently endorse (Rahim, 1983; Weider-Hatfield, 1988). Rahim and Magner (1995) found convergent and discriminant validity for the subscales of obliging, compromising, dominating, avoiding, and integrating in four diverse sample groups for use within organizations concerning how participants would respond to conflict with subordinates, peers, and superiors (Rahim \& Magner, 1995). Cann et al. (2008) used the Rahim Organizational Conflict Inventory-II and found the integrating conflict resolution style to be linked with obliging and negatively linked with avoiding. Shi (2003) describes the more positive conflict resolutions strategies, compromising and integrating, as strategies where a person is understanding, empathic, and leave their fear and defensiveness to self-disclose.

The study done by Ben-Ari and Hirshberg (2009) also assessed conflict perception and attachment style with a sample of junior high students. The authors did not specifically state how relationships attachment was measured. Secure style of attachment most strongly positively related to the compromising coping strategy, $r=0.30$. The avoidant style of attachment was most strongly positively associated with dominating conflict resolution style, and the anxious style of attachment was most strongly related positively to avoiding coping style (Ben-Ari \& Hirshberg, 2009). Bippus and Rollin (2003) conducted a study with undergraduate students and their friend where the participant and their friend reported the participant's attachment style using Bartholomew and Horowitz's (1991) attachment style descriptions. The friends also identified the conflict resolution style the participant normally uses according to the ROCI-II, the relationship maintenance strategies employed, and their relationship satisfaction with the participant. According to friend ratings, participants who were perceived to have a secure attachment style were more likely to use prosocial maintenance strategies, integrating conflict 
resolution style, and have higher relationship satisfaction. Further, the results of Bippus and Rollin (2003) were inconsistent with past research on romantic attachment relationships and conflict behavior. The participants who identified as having a preoccupied attachment style did not significantly endorse prosocial behaviors, and their friends' relationship satisfaction scores were not significantly higher than friends of participants who identified as having dismissive or fearful attachment style. This finding indicates that attachment styles likely play a different role in friendships versus romantic relationships concerning how one deals with interpersonal conflict (Bippus \& Rollin, 2003).

Corcoran and Mallinckrodt (2000) conducted a study with romantic couples to look at attachment style and conflict resolution style. They reported positive correlations between a positive sense of self and others (i.e., secure attachment) with the conflict styles integrating and compromising from the Rahim Organizational Conflict Inventory-II. The authors also found a negative correlation between dismissing attachment (i.e., participants who had a positive view of self and negative view of others) and the integrating and compromising conflict resolution styles. In contrast, the participants with a preoccupied style were more likely to use the avoiding style (Corcoran \& Mallinckrodt, 2000).

Also concerning romantic relationships, Cann et al. (2008) conducted a study with undergraduate students examining attachment, conflict resolution, humor, and relationship satisfaction. The authors found the obliging conflict resolution style was positively correlated with attachment anxiety whereas integrating was negatively correlated with attachment anxiety (Cann et al., 2008). As Shi (2003) explained, those who are higher in attachment anxiety are more concerned about others than the self, that is, the self is unworthy. The integrating and obliging conflict resolution styles were negatively correlated with attachment avoidance, and the 
avoiding and dominating conflict styles were positively linked with attachment avoidance (Cann et al., 2008). These findings for attachment avoidance were consistent with Shi's (2003) description of how a person who scores higher in anxiety is likely to pursue the other person while in conflict, but a person who scores higher in avoidance is likely to withdraw from the other when in conflict (Shi, 2003).

\section{The Present Study}

The purpose of the present study was to examine the association between attachment and conflict resolution during friendship conflict among college students. Research has demonstrated the presence of a relationship between three attachment styles and one's choice of conflict resolution (e.g., Ben-Ari \& Hirshberg, 2009). The current study explored how the attachment dimensions of anxiety and avoidance relate to Rahim's (1983) five conflict resolution styles. This study used the attachment model using dimensions of view of self and view of others from Fraley et al. (2015) and the conflict resolution model employing the dimensions of concern for self and concern for others. The studies reviewed here mostly focused on romantic relationships and measured conflict resolution strategies by asking what strategies participants generally use. The current study measured conflict resolution by first prompting participants to write about a conflict they had in the past 6 months with a friend and rate their perception of the conflict according to how severe (intense, significant, and upsetting) the conflict was. Next, participants described what strategies they employed to resolve the conflict. Participants who had not had a conflict with a friend in the past 6 months responded to a hypothetical conflict. These participants read a vignette with the prompt of imagining it was them who was in the conflict with a friend and rate how severe the conflict was in their perception; the participants then rated how they would resolve the conflict with their friend. Participants were assigned to either the 
real-life conflict or hypothetical conflict; if participants answered yes, they could think of a conflict they have had with a friend in the past 6 months, they were put into the real-life conflict subsample and if they answered no, they could not think of a conflict they have had with a friend in the past 6 months, they were put into the hypothetical conflict subsample. By asking participants this question, there were no restrictions, and every participant was able to participate. Real-life conflict has external validity though it has more variety of severity than did the hypothetical conflict. The hypothetical conflict was an experimental control variable, but it was artificial and therefore participants may have responded in a way that is not representative of how they would respond to a real conflict.

Ben-Ari and Hirshberg (2009) used three attachment styles where the secure style correlated most with the compromising coping strategy, avoidant style correlated most with the dominating coping strategy, and the anxious style most correlated with the avoiding coping style. I used the Fraley et al. (2015) attachment dimensions of attachment anxiety and attachment avoidance. Mapping each cell of Figure 1 onto Figure 2, I hypothesized the following for both the real-life past conflict experience and the hypothetical conflict:

1. Both attachment anxiety and avoidance would negatively correlate with the compromising conflict resolution style.

2. Attachment anxiety would be positively correlated with, and attachment avoidance would be negatively correlated with, obliging conflict resolution style.

3. Both attachment avoidance and anxiety would positively correlate with the avoiding conflict resolution style.

4. Attachment anxiety would be negatively related, and attachment avoidance would be positively correlated, with the dominating conflict resolution style. 
Further, one's attachment behaviors must be activated for one to respond to conflict in a way that aligns with one's attachment. For this reason, I hypothesized that

5. The more severe a participant rates a conflict, the stronger attachment and conflict resolution would be related. That is, conflict severity was hypothesized to moderate the association between attachment and conflict resolution. To my knowledge, this moderation question had not been addressed in the literature before. 


\section{CHAPTER III: METHOD}

\section{Participants}

There were 279 participants recruited from SONA and comprised solely of students attending Illinois State University. No efforts were made to recruit nor restrict based on any demographic variable. A total of 45 participants were eliminated for a variety of reasons: completing less than the required $95 \%$ of the survey, random responding, duplicate participants, and failing to write about a conflict, misunderstanding, or disagreement with a friend in the past 6 months after indicating had a conflict with a friend in the past 6 months. After eliminating the 45 participants, there were 234 total participants, $198(84.6 \%)$ identified as female and 36 $(15.4 \%)$ identified as male. The average age of participants was 19.70 years $(S D=2.40)$, where the youngest participants were 18 years and the oldest participant was 44 years.

In the subsample in which participants wrote about a recent conflict with a friend, there were 173 participants $(86.7 \%$ female; $13.3 \%$ male; 1 participant did not indicate their gender). In the subsample in which participants read a vignette about a hypothetical conflict with a friend, there were 61 participants, $(78.7 \%$ female; $21.3 \%$ male $)$.

Between both subsamples, there were 168 (71.8\%) participants who identified as White, $28(12 . \%)$ participants who identified as African American, 23 (9.8\%) participants who identified as Hispanic/Latino/-a, 12 (5.1\%) participants who identified as biracial, 1 (0.4\%) participant who identified as Asian American or Pacific Islander, $1(0.4 \%)$ who preferred not to answer, no participants who identified as Native American, and $1(.4 \%)$ who identified as "Other." 


\section{Instruments}

\section{Attachment}

The Experiences in Close Relationships-Relationships Structures (ECR-RS; Fraley, Heffernan, Vicary, \& Brumbaugh, 2011) is an inventory with 9 items for four relationship types that assesses attachment style across the two dimensions of anxiety and avoidance. The dimension of avoidance had six items and the dimension of anxiety had 3 items. The ECR-RS measures one's attachment style concerning one's friends. In the real-life conflict subsample, attachment was measured for one friend in particular with whom the participant had a conflict with. For those in the hypothetical conflict subsample measured attachment to friends in general. Each item is self-rated on a 7-point Likert scale, from 1 (strongly disagree) to 7 (strongly agree). A sample item from the measure is, "I talk things over with this person," which would give information concerning one's level of avoidance. The ECR-RS was developed through choosing items with clear wording and discrimination value from other measures followed by factor analyses supporting the two factors of anxiety and avoidance (Fraley et al., 2011). In the current study, the coefficient alpha was 0.86 for the real-life conflict and 0.85 for the hypothetical conflict for attachment avoidance. The attachment anxiety coefficient alpha was 0.84 for the real-life conflict and 0.89 for the hypothetical conflict.

\section{Severity of the Conflict}

How severe, intense, and upsetting a participant experienced the real-life conflict, or would experience the hypothetical conflict was measured by 5-point Likert scales from 1 (not at all) to 5 (extremely). The following are the questions: "How upsetting was this conflict?", "How intense was this conflict?", "How severe was this conflict?”, and "How upsetting was this conflict for your friend?" Severity total was found by averaging the first three items, i.e., "How 
upsetting was this conflict?", "How severe was this conflict?", and "How intense was this conflict?" The coefficient alpha was 0.80 for the real-life conflict and 0.91 for the hypothetical conflict.

\section{Conflict Resolution}

The Rahim Organizational Conflict Inventory-II (ROCI-II) developed by Rahim (1983) was used. The inventory has 28 items, and a 5-point Likert scale, with higher scores indicating higher endorsement. The scores indicate the participant's primary conflict resolution style among compromising, obliging, dominating, integrating, and avoiding. An example item is, "I try to investigate an issue with my peer to find a solution acceptable to us". The ROCI-II was developed through feedback followed by factor analyses. Adequate internal consistency and moderate to good support for test-retest reliability have been found (Rahim, 1983; WeiderHatfield, 1988). Coefficient alphas for the real-life conflict were as follows: 0.88 for integrating, 0.85 for obliging, 0.77 for dominating, 0.79 for avoiding, and 0.80 for compromising. Coefficient alphas for the hypothetical conflict are as follows: 0.90 for integrating, 0.80 for obliging, 0.83 for dominating, 0.88 for avoiding, and 0.84 for compromising.

\section{Procedure}

Participants were recruited from the Department of Psychology human participants pool and offered course extra credit. The participants completed the survey online through Qualtrics. After providing informed consent, participants filled out demographic information and then were asked if they could think of a conflict, misunderstanding, or disagreement they have had with a friend in the past 6 months.

If the participant chose yes to this question, they were assigned to the real-life conflict subsample. They were directed to type the initials of the friend they were thinking of and fill out 
the ECR-RS concerning this friend. Next, these participants were prompted to write a description of the conflict, disagreement, or misunderstanding they had with their friend and to rate how severe, intense, and upset the participant experienced the conflict. Participants wrote about conflicts such as friends not sharing house chores equally when living together, friends ditching the participant for a variety of reasons, friends disagreeing about beliefs and expectations, and friends prioritizing romantic partners over friends. Following this, participants completed the ROCI-II concerning how they resolved the conflict with their friend. They were then taken to a debriefing page.

If the participants chose no to this question (i.e., that they could not think of a conflict they have had with a friend in the past 6 months), they were assigned to the hypothetical-conflict subsample. Participants were then directed to fill out the ECR-RS concerning their friends in general. Participants were randomly assigned to one of two vignettes and were prompted to read a vignette about two friends who had a conflict. The first vignette, which was designed to be a more severe conflict, was as follows:

Imagine that you and your best friend have been friends since you were kids. Recently, you both had romantic feelings for the same person. Your friend recently went out on a date with this person, and now they are spending a lot of time together. Your friend knows this is devastating for you, and to make matters worse, your friend has been spending less time with you lately, and you feel like you want to spend less time with your friend. It seems that both you and your friend need to work through this issue to save your friendship.

The second vignette, which was designed to be a less severe conflict, had parallel wording but described a more trivial source of conflict: 
Imagine that you and your best friend have been friends since you were kids. This semester, you had the same class together. Your friend had agreed to study with you for a test you both have the next day, but your friend cancels at the last minute, telling you that they want to study alone. Your friend knows this is inconvenient for you, particularly since you had missed a class and were counting on your friend's lecture notes. It seems that both you and your friend need to work through this issue to do well in class.

Assignment to vignette condition was randomized. Following the presentation of one of these two vignettes, participants rated the severity of the hypothetical conflict and completed the ROCI-II according to how they thought they would resolve the conflict with this friend. Finally, participants were taken to a debriefing page explaining the purpose of the study.

\section{Plan for Data Analysis}

The subsamples who responded to a real-life conflict versus the hypothetical conflict were separated in the analyses and were considered independent samples. Correlations were run to determine the link between attachment dimensions and primary conflict resolution styles. Specifically, the ECR-RS scores for attachment anxiety and attachment avoidance were correlated with the ROCI-II to determine the relationships between attachment and conflict resolution style. To test for moderation, Hayes' (2017) PROCESS macro for SPSS was used. Participants' ratings of severity of the conflict ( 3 items) were averaged to get a total score for each participant and analyzed as a moderator between conflict resolution and attachment. 


\section{CHAPTER IV: RESULTS}

\section{Real-Life Conflict Subsample}

The real-life conflict subsample consisted of participants who identified a past conflict with a friend in the last 6 months. The participants completed measures of attachment to this specific friend and measures of conflict resolution for the actual conflict the participant decided to write about. The means and standard deviations of the measures among participants who identified an actual conflict are reported in Table 1.

Table 1

Means and Standard Deviations of Measures Concerning Real-Life Conflict

\begin{tabular}{lll}
\hline Measure & $M$ & $S D$ \\
\hline Attachment Anxiety & 2.86 & 1.64 \\
Attachment Avoidance & 3.16 & 1.40 \\
Obliging & 2.95 & 0.89 \\
Dominating & 2.67 & 0.85 \\
Avoiding & 2.93 & 0.91 \\
Integrating & 3.41 & 0.91 \\
Compromising & 3.10 & 0.93 \\
Severity Total & 3.15 & 0.96 \\
\hline
\end{tabular}

Correlations among study variables for participants who identified a real-life conflict with a peer are reported in Table 2. For Hypothesis 1, I predicted the compromising conflict resolution style would be negatively correlated with both attachment anxiety and attachment 
avoidance. This hypothesis was partially supported. Attachment avoidance to the friend had a negative correlation with compromising in response to the conflict with that friend, $r=-0.28, p$ $<0.01$. Contrary to my hypothesis, compromising was positively correlated with attachment anxiety to the friend, $r=0.16, p=0.03$.

Table 2

Correlations from Measures Concerning Real-Life Conflict

\begin{tabular}{lccccccc}
\hline Variables & 1 & 2 & 3 & 4 & 5 & 6 & 7 \\
\hline 1. Attachment & - & & & & & \\
Anxiety & & & & & & \\
2. Attachment & $0.23^{* *}$ & - & & & & & \\
Avoidance & & & & & & & \\
3. Obliging & $0.27^{* *}$ & $-0.19^{*}$ & - & & & & \\
4. Dominating & $-0.18^{*}$ & -0.09 & -0.13 & - & & & \\
5. Avoiding & 0.08 & $0.17^{*}$ & 0.12 & -0.13 & - & & \\
6. Integrating & 0.08 & $-0.31^{* *}$ & $0.49^{* *}$ & $0.23^{* *}$ & $-0.26^{* *}$ & - & \\
7. Compromising & $0.16^{*}$ & $-0.28^{* *}$ & $0.61^{* *}$ & 0.14 & -0.12 & $0.77^{* *}$ & - \\
8. Severity Total & $0.16^{*}$ & -0.02 & -0.15 & 0.09 & -0.03 & -0.02 & -0.11 \\
& & & & & & &
\end{tabular}
Note: ${ }^{*} p<.05 .{ }^{* *} p<.01$.

For Hypothesis 2, I predicted that the obliging conflict resolution style would be positively correlated with attachment anxiety and negatively correlated with attachment avoidance. This hypothesis was supported. Attachment anxiety was positively related to the 
obliging conflict resolution style, $r=0.27, p<0.01$, and attachment avoidance was negatively correlated with the obliging conflict resolution style, $r=-0.19, p=0.01$.

For Hypothesis 3, I predicted that the avoiding conflict resolution style would be positively correlated with both attachment anxiety and avoidance; this hypothesis was partially supported. Attachment anxiety had a non-significant correlation with the avoiding conflict resolution style, $r=0.08, p=0.29$, but attachment avoidance was positively correlated with the avoiding conflict resolution style, $r=0.17, p=0.02$.

For Hypothesis 4, I predicted that attachment avoidance would be positively correlated with the dominating conflict resolution style whereas attachment anxiety would be negatively correlated with the dominating conflict resolution style. This hypothesis was partially supported. Attachment avoidance was not significantly correlated with the dominating conflict resolution style, $r=-0.09, p=0.26$, but attachment anxiety was negatively correlated with the dominating conflict resolution style, $r=-0.18, p=0.01$.

Lastly, Hypothesis 5 predicted that the relationship between attachment anxiety and avoidance and conflict resolution would be moderated by the ratings of severity of the conflict. Specifically, I predicted that the associations between attachment to a friend and conflict resolution concerning a real-life conflict with that friend would be stronger when the severity of that conflict was high (versus when severity was low). I tested this moderation hypothesis for 8 attachment/conflict-resolution relations because there were 2 measures of attachment and 5 measures of conflict resolution. Moderation was tested with Hayes' (2017) PROCESS macro for SPSS. Table 3 reports the changes in $R^{2}$ (see Real Conflict column). Only one of these 10 relations was moderated by conflict severity. Specifically, this moderation hypothesis was supported between attachment avoidance and the dominating conflict resolution style. Figure 1 
displays this moderation effect. When the conflict was severe, there was a weak, positive association between attachment avoidance and the dominating style, $b=.08, p=.23$. When conflict severity was low, there was a negative association between attachment avoidance and the dominating style, $b=-.15, p=.01$. This significant moderation effect supports the use of the dominating conflict resolution style was most likely when both attachment avoidance and the severity of the conflict were high.

Table 3

Moderation of Severity Ratings on Attachment Anxiety and Avoidance with Conflict Resolution Styles

\begin{tabular}{llll}
\hline Focal Predictor & Criterion Variable & Real Conflict $\Delta R^{2}$ & Vignette Conflict $\Delta R^{2}$ \\
\hline Attachment Anxiety & Compromising & 0.00 & 0.01 \\
& Avoiding & 0.01 & 0.00 \\
& Dominating & 0.00 & 0.00 \\
& Obliging & 0.01 & 0.00 \\
Attachment Avoidance & Compromising & 0.00 & 0.00 \\
& Avoiding & 0.00 & 0.02 \\
& Dominating & $0.03 *$ & 0.06 \\
& Obliging & 0.01 & 0.01
\end{tabular}

Note: $* p<0.05$. 


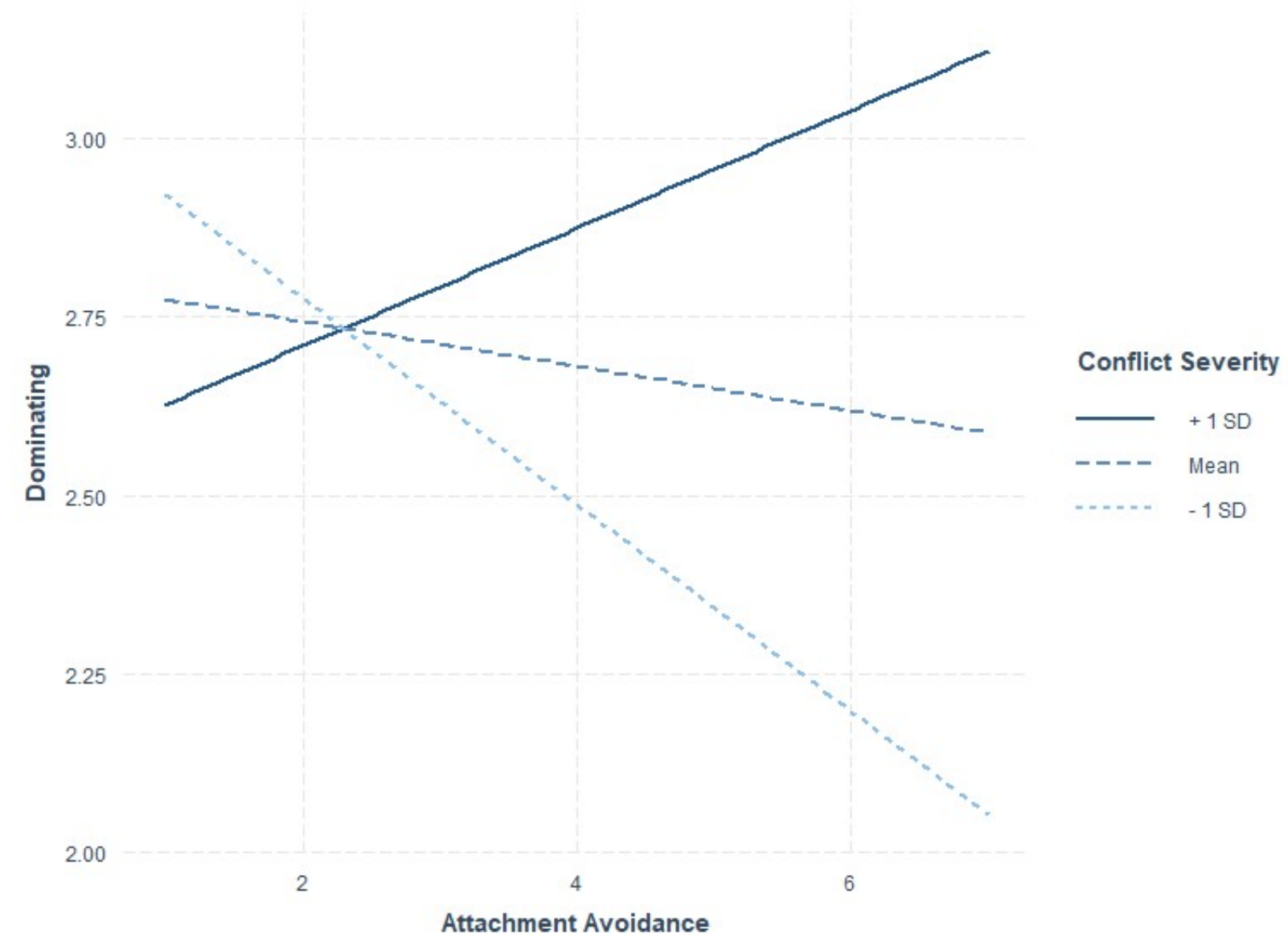

Figure 3 Moderation effect of conflict severity on the association between attachment avoidance and dominating conflict-resolution style.

\section{Hypothetical-Conflict Subsample}

The hypothetical-conflict subsample consisted of participants who read a vignette where they imagined that the conflict in a vignette occurred to them. The participants completed measures of attachment in regards to their friends in general and measures of conflict resolution in response to the conflict in the vignette. A total of 31 participants read the vignette about romantic feelings, and 30 participants read the vignette about the study session. The means and standard deviations concerning hypothetical conflict are reported in Table 4. 
Table 4

Means and Standard Deviations of Measures Concerning Hypothetical Conflict

\begin{tabular}{lll}
\hline Measure & $M$ & $S D$ \\
\hline Attachment Anxiety & 2.98 & 1.68 \\
Attachment Avoidance & 2.85 & 1.17 \\
Obliging & 3.13 & 0.66 \\
Dominating & 2.52 & 0.82 \\
Avoiding & 2.69 & 0.93 \\
Integrating & 3.68 & 0.73 \\
Compromising & 3.44 & 0.80 \\
Severity Total & 2.93 & 1.00 \\
\hline
\end{tabular}

As a manipulation check, I conducted an independent-samples $t$-test to determine whether the two vignettes differed in their perceived severity. There was a significant effect for vignette type, $t(59)=2.44, p=0.02, d=0.63$. The vignette concerning romantic feelings $(M=3.23, S D=$ $0.80, n=30)$ was rated as more severe than the vignette concerning a study session $(M=2.63$, $S D=1.09, n=31)$

Correlations from the measures concerning a hypothetical conflict are reported in Table 5. For Hypothesis 1, I predicted that the compromising conflict resolution style would negatively correlate with both attachment anxiety and avoidance. This hypothesis was not supported. Attachment anxiety was not significantly correlated to the compromising conflict resolution style, $r=0.05, p=0.69$, and attachment avoidance was not significantly related to the compromising conflict resolution style, $r=-0.21, p=0.11$. Moreover, these results do not match 
the results of the real-life conflict. The compromising conflict resolution style had a negative correlation with attachment avoidance and a positive correlation with attachment anxiety in the prior subsample.

Table 5

Correlations from Measures Concerning Hypothetical Conflict

\begin{tabular}{|c|c|c|c|c|c|c|c|}
\hline Variables & 1 & 2 & 3 & 4 & 5 & 6 & 7 \\
\hline 1. Attachment & - & & & & & & \\
\hline Anxiety & & & & & & & \\
\hline 2. Attachment & $0.50 * *$ & - & & & & & \\
\hline Avoidance & & & & & & & \\
\hline 3. Obliging & $0.38 * *$ & 0.03 & - & & & & \\
\hline 4. Dominating & 0.19 & 0.11 & -0.20 & - & & & \\
\hline 5. Avoiding & $0.35 * *$ & $0.37 * *$ & $0.51 * *$ & -0.08 & - & & \\
\hline 6. Integrating & -0.09 & $-0.55 * *$ & 0.10 & 0.14 & $-0.36 * *$ & - & \\
\hline 7. Compromising & 0.05 & -0.21 & -0.01 & $0.33 *$ & -0.24 & $0.64 * *$ & - \\
\hline 8. Severity Total & 0.24 & 0.15 & -0.05 & $0.31 *$ & 0.07 & 0.00 & 0.20 \\
\hline
\end{tabular}

For Hypothesis 2, I predicted that the obliging conflict resolution style would be positively correlated with attachment anxiety and negatively correlated with attachment avoidance. This hypothesis was partially supported. Attachment anxiety was positively related to the obliging conflict resolution style, $r=0.38, p<0.01$. Attachment avoidance was not related to 
the obliging conflict resolution style, $r=0.03, p=0.80$. There was a negative correlation between attachment avoidance and the obliging conflict resolution style in the real-life conflict results.

For Hypothesis 3, I predicted that the avoiding conflict resolution style would be positively correlated with both attachment anxiety and avoidance; this was supported. Attachment anxiety was positively related to the avoiding conflict resolution style, $r=0.35, p=$ 0.01, and so was attachment avoidance, $r=0.37, p<0.01$. These results for attachment avoidance match the results from the real-life conflict. Attachment anxiety was not related to the avoiding conflict resolution style in the real-life conflict results.

For Hypothesis 4, I predicted that attachment avoidance would be positively correlated with the dominating conflict resolution style, whereas attachment anxiety was hypothesized to be negatively correlated with the dominating conflict resolution style, but this was not supported. Neither attachment avoidance, $r=0.11, p=0.39$, nor attachment anxiety, $r=0.19, p=0.13$, were related to the dominating conflict resolution style. These results are different from the reallife conflict; attachment anxiety had a negative correlation with the dominating conflict resolution style.

Lastly, for Hypothesis 5, I predicted that the relationship between attachment anxiety and avoidance and conflict resolution would be moderated by the ratings of severity of the conflict. Moderation was tested with Hayes' (2017) PROCESS macro for SPSS. Table 3 (presented earlier) reports the changes in $R^{2}$. This hypothesis was not supported for any relationship between attachment and conflict resolution. These results are similar to those from the real-life conflict with the exception that severity significantly moderated the relationship between 
attachment avoidance and the dominating conflict resolution style in the real-life conflict subsample.

Moderation was also tested without severity ratings but with vignette type instead because the vignette concerning romantic feelings was rated as significantly more severe than the conflict concerning a study session. Therefore, vignette type was also analyzed as a moderator to determine if the relationship between attachment anxiety and avoidance and conflict resolution would be strengthened depending on which vignette a participant was assigned. This test did not produce a strengthened relationship between attachment anxiety and avoidance and conflict resolution. 


\section{CHAPTER V: DISCUSSION}

The present study focused on the relationship between attachment and conflict resolution within friendship among college students. The relationship between attachment and conflict resolution has been demonstrated in past research, such as Ben-Ari and Hirshberg's (2009) study. Specifically, the current study examined how attachment anxiety and avoidance related to the five conflict resolution styles, i.e., compromising, integrating, avoiding, dominating, and obliging, theorized by Rahim (1983). The attachment model used was from Fraley et al. (2015), which includes the dimensions view of self and view of others. The majority of past research on conflict resolution has been conducted in the context of romantic relationships in which participants rated their conflict resolution styles based on how they generally resolved conflict. The current study measured conflict resolution by prompting participants to consider a real-life conflict subsample to write about a conflict they have had with a friend during the past 6 months, rate how severe the conflict was, and then rate the styles they employed to resolve the conflict. The participants in the hypothetical-conflict subsample read a vignette and were given the prompts to imagine it was them, rate how severe the conflict would have been for them, and then rate how they would resolve the conflict.

The following discussion of the present study's results must account for differences between this study and prior studies. Previous research measured conflict resolution by asking participants how they generally respond to conflict within romantic or friend relationships. The current study measured conflict resolution by asking participants to rate how they resolved, or would resolve, the conflict in one specific situation with a specific friend or friends in general. Additionally, the hypothetical conflict was theoretical, meaning participants may have answered in a way that is different from how they would handle the conflict in real life. Finally, the current 
study examined conflict resolution in friendships, whereas other studies (e.g., Corcoran \& Mallinckrodt, 2000) focused on romantic relationships.

\section{Discussion of Results}

Hypothesis 1 predicted that the compromising conflict resolution style would be negatively correlated with both attachment anxiety and attachment avoidance. In the real-life conflict subsample, compromising had a negative correlation with attachment avoidance but a positive correlation with attachment anxiety. In the hypothetical-conflict subsample, compromising had a non-significant relationship with both attachment anxiety and avoidance. Previous research has found adults low in attachment anxiety and avoidance are more likely to use prosocial, effective, and more productive strategies when having relationship conflict (BenAri \& Hirshberg, 2009; Heinze et al., 2018; Mikulincer 1998; Mikulincer, Orbach, \& Iavnieli 1998). A secure attachment style has been found to be most strongly positively correlated with compromising, which is a more positive conflict resolution style characterized by understanding and empathy (Ben-Ari \& Hirshberg, 2009; Corcoran \& Mallinckrodt, 2000; Shi, 2003). The results from the current study are similar to previous research; the dismissing attachment, i.e., positive view of self and negative view of others, had a negative correlation with the compromising conflict resolution style (Corcoran \& Mallinckrodt, 2000). Participants high in attachment avoidance may not care to put effort into resolving a conflict by compromising in their friendship. Participants high in attachment anxiety felt less willing to take a stand even when they felt strongly and were willing to allow their friend to assert their position, which was unexpected.

Hypothesis 2 predicted that the obliging conflict resolution style would be positively correlated with attachment anxiety and negatively correlated with attachment avoidance. In the 
real-life conflict subsample, obliging was positively correlated with attachment anxiety and negatively correlated with attachment avoidance. In the hypothetical-conflict subsample, obliging was positively related to attachment anxiety but was not related to attachment avoidance. These results are similar to Cann et al.'s (2008) study in which the authors found attachment anxiety to positively relate to the obliging conflict resolution style. Participants high in attachment anxiety may be worried about preserving their relationship and therefore would want to please the other person. Participants high in attachment avoidance may not use the obliging style because they view themselves positively and others negatively and may care to only get a positive resolution for themselves.

Hypothesis 3 predicted that the avoiding conflict resolution style would be positively correlated with both attachment anxiety and avoidance. In the real-life conflict subsample, avoiding had a non-significant correlation with attachment anxiety and a positive correlation with attachment avoidance. In the hypothetical conflict, the avoiding style was positively related to both attachment anxiety and avoidance. Cann et al. (2008) also found attachment anxiety and avoidance to correlate with the avoiding conflict resolution style. Participants high in attachment avoidance may avoid resolving conflict and not bother resolving conflict within friendships. Participants high in anxiety may avoid resolving the conflict for fear they may lose their friend.

Hypothesis 4 predicted that attachment avoidance would be positively correlated with the dominating conflict-resolution style whereas attachment anxiety would be negatively correlated with the dominating style. This hypothesis was partially supported in the real-life conflict subsample; dominating had a non-significant correlation with attachment avoidance and a negative correlation with attachment anxiety. In the hypothetical-conflict subsample, dominating was not related to either attachment avoidance or anxiety. The present study did not replicate 
Corcoran and Mallinckrodt's (2000) finding that participants with the preoccupied (anxious) style of attachment were more likely to use the dominating conflict resolution style within romantic relationships. The current study also did not find high attachment avoidance to be positively correlated with the dominating conflict resolution style, unlike Ben-Ari and Hirshberg (2009) and Cann et al. (2008) who found participants with the avoidant attachment style to use the dominating conflict resolution style. Participants high in attachment avoidance may not have used the dominating style in this study because they do not care enough about the relationship to put forth effort to resolve the conflict within their friendship. Participants high in attachment anxiety may not have used the dominating style because they are more worried about preserving the relationship.

Hypothesis 5 predicted that the relationship between attachment anxiety and avoidance and conflict resolution would be moderated by the ratings of conflict severity. Specifically, I predicted that the associations between attachment to a friend and conflict resolution concerning a real-life conflict with that friend would be stronger when the severity of that conflict was high (versus when severity was low). This hypothesis was not supported except for the real-life conflict subsample where severity significantly moderated the relationship between attachment avoidance and the dominating conflict resolution style. Severity may not have mattered in the majority of the moderation tests due to the severity questions not being empirically validated and severity not being a true moderator between attachment and conflict resolution. Perhaps both low and high severity activated the attachment system, resulting in no real differences. Another possibility is actual experienced level of severity may require insight into the underlying message one receives when confronted with conflict. 
The results from the real-life conflict and the hypothetical-conflict subsamples were similar in regard to several correlations: attachment anxiety was positively related with the obliging style, attachment avoidance was positively linked with the avoiding style, and attachment avoidance was negatively correlated with the compromising and integrating styles. A correlation in the real-life conflict subsample that did not replicate in the hypothetical-conflict subsample was the positive relationship between attachment anxiety and the compromising style. This positive correlation between attachment anxiety and the compromising style was a surprise since I theorized participants high in anxiety would worry too much about losing their friend to try and make sure the friend was content in the relationship. Attachment anxiety had a positive relationship with the avoiding conflict resolution style in the hypothetical-conflict subsample, which was not replicated in the real-life conflict subsample. This difference may have occurred because the conflict was hypothetical and may not have seemed like a real possibility for participants, leading participants high in attachment anxiety to be more likely to avoid resolution and withdraw. In the real-life conflict, negative relationships were found between attachment anxiety with the dominating conflict resolution style and attachment avoidance with the obliging conflict resolution style. The negative relationship between attachment anxiety and dominating in the real-life conflict was unique since attachment anxiety was not found to have significant negative links with any conflict resolution styles in the hypothetical conflict. Participants in the real-life conflict subsample were reporting on the actual style they used in a true conflict whereas participants in the hypothetical-conflict subsample were reporting on the style they believe they would use in a given conflict. Real actions sometimes differ from what we believe we would do, or what we would like to think we would do. 


\section{Limitations and Future Directions}

This study had several limitations. The population for this study was intended to be representative of adults, but the majority of the sample were emerging adults and were solely in college. Additionally, females made up majority of the sample. The sample would ideally have been equal in gender with more variability in age and education level. A larger sample would be beneficial to increase strength of the relationships among attachment anxiety and avoidance with the conflict resolution styles and would be more of a representative sample of adults. To my knowledge, gender and education-level differences have not been found in styles of conflict resolution patterns, but having a sample equal in gender with variability in education level could have allowed me to test for gender and education-level differences.

This study also used an online method where participants self-reported on the measures. This form of measurement is a limitation due to the participants only using self-report without peer reports or observations. Continuing this research could include having adults of all ages bring a friend into the lab and report on each other, which would strengthen the study by increasing validity. Further, the two friends could work on a conflict in the lab while being video recorded, and researchers could code the styles of conflict resolution being used. Additional ways to extend this research could be by asking participants about a conflict concerning two different friends to determine if people resolve conflict differently depending on which friend the conflict is with, having participants explain their reason for the way he or she resolved the conflict, and having two friends report on the same conflict.

The participants were self-selected into the real-life or hypothetical subsample. This is a limitation because participants who stated they could think of a conflict with a friend in the past 6 months could be particularly conflictual people; participants who stated they could not think of 
a conflict with a friend in the past 6 months may be people who do not have many close friends. Also, a limitation of comparing results concerning the real-life conflict and hypothetical conflict is that, in the real-life conflict subsample, the participants answered the ECR-RS specifically about one friend, whereas the hypothetical-conflict participants answered about friends in general. Though attachment is relatively stable throughout a person's life and across relationships (Fraley \& Shaver, 2008), attachment could potentially be different among friends. Research could examine whether attachment differs for different friends, whether attachment differs among other types of relationships, and what variables may influence the difference in attachment anxiety and avoidance, such as change over time within relationships. Variables might be the length of time the friendship has present or the emotional closeness subjectively felt by both parties. A longitudinal study examining if conflict resolution style changes over time within friendships could help to explain the role attachment has with conflict-resolution styles.

\section{Implications}

The results of this study support the existence of a relationship between attachment and conflict-resolution patterns, specifically among attachment anxiety and avoidance and obliging, dominating, avoiding, and compromising conflict-resolution styles. The attachment style one develops as an infant plays a role in their friendships; attachment from infancy plays a similar role in other relationships (Fraley \& Shaver, 2008). People who have more fear of abandonment (i.e., higher attachment anxiety) are likely to use conflict resolution styles that would result in less risk of their friend leaving them and maintaining harmony in the relationship. However, people who consistently use the obliging style may be unhappy in their relationships because they are consistently concerned for their friends. People who have a higher sense of self-worth and expectation of others to disappoint them, i.e., higher attachment avoidance, are likely to 
avoid resolving the conflict altogether and not bother with putting forth the effort for the relationship. People in this situation may frequently leave friendships and feel this is their support for their expectation of disappointment.

The results have clinical implications as well. Within therapeutic relationships with clients, attachment and conflict resolution styles play a role (O'Connor, Kivlighan, Hill, \& Gelso, 2019; Taylor, Rietzshel, Danquah, \& Berry, 2015). Clients who are higher in attachment anxiety would likely attempt to make the therapist happy. Clients who are higher in attachment avoidance may simply drop out of therapy and forego resolving conflict or repairing the relationship. Clinicians could assess clients' attachment anxiety and avoidance and educate them about what attachment anxiety and avoidance means for their relationships. Becoming aware of how their attachment is demonstrated in their relationships and how their primary conflict resolution style affects their relationships could lead to healthier relationships. A therapist could potentially offer a psychoeducational group focused on teaching about attachment anxiety and avoidance and bring awareness to how attachment plays out in their friendships, specifically conflict in friendships. 


\section{REFERENCES}

Ainsworth, M. S., Blehar, M.C., Waters, E., \& Wall, S. (1978). Patterns of Attachment. Hillsdale, NJ: Erlbaum.

Argyle, M., \& Henderson, M. (1984). The Rules of Friendship. Journal of Social and Personal Relationships, 1(2), 211-237. doi: 10.1177/0265407584012005

Bartholomew, K., \& Horowitz, L.M. (1991). Attachment styles among young adults: A test of a four-category. Journal of Personality and Social Psychology, 61(2), 226-244. doi:10.1037/0022-3514.61.2.226

Ben-Ari, R., \& Hirshberg, I. (2009). Attachment styles, conflict perception, and adolescents' strategies of coping with interpersonal conflict. Negotiation Journal, 25(1), 59-82. doi:10.1111/j.1571-9979.2008.00208.x

Berndt, T. J. (2004). Children's friendships: Shifts over a half-century in perspectives on their development and their effects. Merrill-Palmer Quarterly, 50(3), 206-223. doi:10.1353/mpq.2004.0014

Bippus, A.M., \& Rollin, E. (2003). Attachment style differences in relational maintenance and conflict behaviors: Friends’ Perceptions. Communication Reports, 16(2), 113-123. doi:10.1080/08934210309384494

Bowlby, J. (1973). Attachment and loss. Vol. 2. Separation. New York: Basic Books.

Brougham, R.B., Zail, C.M., Mendoza, C.M., \& Miller, J.R. (2009). Stress, sex differences, and coping strategies among college students. Curr Psychol, 28, 85-97. doi:10.1007/s12144009-9047-0 
Buote, V.M., Pancer, S.M., Pratt, M.W., Adams, G., Birnie-Lefcovitch, S., Polivy, J, Wintre, M.G. (2007). The importance of friends: Friendship and adjustment among $1^{\text {st }}$-year university students. Journal of Adolescent Research, 22(6), 665-689. doi:10.1177/0743558407306344

Canary, D.J., Cupach, W.R., \& Messman, S.J. (1995). Relationship conflict: Conflict in parentchild, friendship, and romantic relationships. Thousand Oaks, CA. Sage.

Cann, A., Norman, M.A., Welbourne, J.L., \& Calhoun, L.G. (2008). Attachment styles, conflict styles, and humor styles: Interrelationships and associations with relationships satisfaction. European Journal of Personality, 22, 131-146. doi: 10.1002/per.666

Carver, C.S., Scheier, M.F., \& Weintraub, J.K. (1989). Assessing coping strategies: A theoretically based approach. Journal of Personality and Social Psychology, 56(2), 267283. doi:10.1037/0022-3514.56.2.267

Corcoran, K.O., \& Mallinckrodt, B. (2000). Adult attachment, self-efficacy, perspective taking, and conflict resolution. Journal of Counseling and Development, 78(4), 473-483. doi:10.1002/j.1556-6676.2000.tb01931

Ehrlich, K.B., Dykas, M.D., \& Cassidy, J. (2012). Tipping points in adolescent adjustment: Predicting social functioning from adolescents' conflict with parents and friends. Journal of Family Psychology, 26(5), 776-783. doi: 10.1037/a0029868

Erikson, E. H. (1980). Identity and the life cycle. New York, NY: W W Norton \& Co. Retrieved from http://libproxy.lib.ilstu.edu/login?url=https://search.ebscohost.com/login.aspx?direct=true \&db=psyh\&AN=1994-97386-000\&site=ehost-live\&scope $=$ site

Folkman, S., \& Lazarus, R.S. (1980). An analysis of coping in a middle-aged community sample. Journal of Health and Social Behavior, 21(3), 219-239. 
Fraley, R.C., \& Davis, K. (1997). Attachment formation and transfer in young adults' close friendships and romantic relationships. Personal Relationships 4(2), 131-144. doi: 10.1111/j.1475-6811.1997.tb00135.x

Fraley, R.C., Heffernan, M.E., Vicary, A.M., \& Brumbaugh, C.C. (2011). The experiences in close relationships — relationship structure questionnaire: A method for assessing attachment orientations across relationships. Psychological Assessment, 23(3), 615-625. doi: 10.1037/a0022898.

Fraley, R.C., Hudson, N.W., Heffernan, M.E., \& Segal, N. (2015). Are adult attachment styles categorial or dimensional? A taxometric analysis of general and relationship-specific attachment orientation. Journal of Personality and Social Psychology, 109(2), 354-368. doi:10.1037/pspp0000027

Fraley, R.C., \& Shaver, P.R. (2008). Attachment theory and its place in contemporary personality theory and research. In O.P. John, R.W. Robins, \& L.A. Pervin (Eds.), Handbook of Personality: Theory and Research ( $3^{\text {rd }}$ Ed., pp. 518-541). New York: The Guilford Press.

Fuhrman, R. W., Flannagan, D., \& Matamoros, M. (2009). Behavior expectations in cross-sex friendships, same-sex friendships, and romantic relationships. Personal Relationships, 16(4), 575-595. doi: 10.1111/j.1475-6811.2009.01240.x

Gorrese, A., \& Ruggieri, R. (2012). Peer attachment: A meta-analytic review of gender and age differences and associations with parent attachment. Journal of Youth and Adolescence, 41, 650-672. doi: 10.1007/s10964-012-9759-6 
Griffin, D., \& Bartholomew, K. (1994). Models of self and other: Fundamental dimensions underlying measures of adult attachment. Journal of Personality and Social Psychology, 67(3), 430-445. doi:10.1037/0022-3514.67.3.430

Hartup, W.W., B. Laursen, M.I., Stewart, \& A. Eastenson. (1988). Conflict and the friendship relations of young children. Child Development 59(6), 1590-1600. doi: 10.2307/1130673

Heinze, J.E., Cook, S.H., Wood, E.P., Dumadag, A.C., \& Zimmerman, M.A. (2018). Friendships attachment style moderates the effect of adolescent exposure to violence on emerging adult depression and anxiety trajectories. $J$ Youth Adolescence, 47, 177-193. doi: $10.1007 / \mathrm{s} 10964-017-0729-\mathrm{x}$

Herrera, C., \& Dunn, J. (1997). Early experiences with family conflict: Implications for arguments with a close friend. Developmental Psychology, 33(5), 869-881. doi:10.1037/0012-1649.33.5.869

Hojjat, M., \& Moyer, A. (2017). The psychology of friendship. New York, NY, US: Oxford University Press.

Johnson, D. W., \& Johnson, R.T. (1996). Conflict resolution and peer mediation programs in elementary schools: A review of the research. Review of Educational Research 66(4), 459-506. doi:10.3102/00346543066004459

Laursen, B. (1995). Conflict and social interaction in adolescent relationships. Journal of Research on Adolescence, 5(1), 55-70. doi:10.1207/s15327795jra05013 
Lewis, D. M. G., Al-Shawaf, L., Russell, E. M., \& Buss, D. M. (2015). Friends and happiness: An evolutionary perspective on friendship. In M. Demir (Ed.), Friendship and happiness: Across the life-span and cultures. (pp. 37-57). New York, NY: Springer Science + Business Media. Retrieved from http://libproxy.lib.ilstu.edu/login?url=https://search.ebscohost.com/login.aspx?direct=true $\& \mathrm{db}=$ psyh \&AN=2015-19322-003\&site $=$ ehost-live\&scope $=$ site

Marchand, J.F. (2004). Husbands' and wives' marital quality: The role of adult attachment orientations, depressive symptoms, and conflict resolution behaviors. Attachment \& Human Development, 6(1), 99-112. doi:10.1080/14616730310001659575

Mikulincer, M. (1998). Adult attachment style and individual differences in functional versus dysfunctional experiences of anger. Journal of Personality and Social Psychology, 74(2), $513-524$.

Mikulincer, M., I. Orbach, \& D. Iavnieli. (1998). Adult attachment style and affect regulation: Strategic variations in subjective self-other similarity. Journal of Personality and Social Psychology 75(2): 436-448.

O’Connor, S., Kivlighan, D. M., Jr., Hill, C. E., \& Gelso, C. J. (2019). Therapist-client agreement about their working alliance: Associations with attachment styles. Journal of Counseling Psychology, 66(1), 83-93. https://doiorg.libproxy.lib.ilstu.edu/10.1037/cou0000303

Oswald, D. L., \& Clark, E. M. (2003). Best friends forever?: High school best friendships and the transition to college. Personal Relationships, 10(2), 187-196. doi: 10.1111/14756811.00045 
Perlman, D., Stevens, N.L., \& Carcedo, R.J. (2015). Friendship. IN M. Mikulincer et al. (Eds.), APA handbook of personality and social Psychology, Vol. 3. Interpersonal relations (pp. 463-493). Washington, DC: American Psychology Association. doi: 10.1037/14344-017

Piaget, J. (1932). The moral judgment of the child. Oxford: Harcourt, Brace. Retrieved from http://libproxy.lib.ilstu.edu/login?url=https://search.ebscohost.com/login.aspx?direct=true $\& \mathrm{db}=$ psyh $\& A \mathrm{~N}=1933-00335-000 \&$ site $=$ ehost-live $\&$ scope $=$ site

Pittman, L.D., \& Richmond, A. (2008). University belonging, friendship quality, and psychological adjustment during the transition to college The Journal of Experimental Education, 76(4), 343-361. doi: 10.3200/JEXE.76.4.343-362

Rahim, M.A. (1983). A measure of styles of handling interpersonal conflict. The Academy of Management Journal, 26(2), 368-376. doi: 10.2307/255985

Rahim, M.A., \& Magner, N.R. (1995). Confirmatory factor analysis of the styles of handling interpersonal conflict: First-order factor model and its invariance across groups. Journal of Applied Psychology, 80(1), 122-132. doi: 10.1037/0021-9010.80.1.222

Rosenthal, N. L., \& Kobak, R. (2010). Assessing adolescents’ attachment hierarchies: Differences across developmental periods and associations with individual adaptation. Journal of Research on Adolescence, 20(3), 678-706. doi: 10.1111/j.15327795.2010.00655.x

Rusbult, C. E., Zembrodt, I. M., \& Gunn, L. K. (1982). Exit, voice, loyalty, and neglect: Responses to dissatisfaction in romantic involvements. Journal of Personality and Social Psychology, 43(6), 1230-1242. https://doi-org.libproxy.lib.ilstu.edu/10.1037/00223514.43.6.1230 
Rybak, A., \& McAndrew, F.T. (2006). How do we decide whom our friends are? Defining levels of friendship in Poland and the United States. The Journal of Social Psychology, 146(2), 147-163. doi: 10.3200/SOCP.146.2.147-163

Salvas, M., Vitaro, F., Brendgen, M., Dionne, G., Tremblay, R.E., \& Boivin, M. (2014).

Friendship conflict and the development of generalized physical aggression in the early school years: A genetically informed study of potential moderators. Developmental Psychology, 50(6), 1794-1807. doi:10.1037/a0036419

Sebanc, A.M., Kearns, K.T., Hernandez, M.D., \& Galvin, K.B. (2007). Predicting have a best friend in young children: Individual characteristics and friendship features. The Journal of Genetic Psychology, 168(1), 81-95. doi: 10.3200/GNTP.168.1.81-96

Seiffge-Krenke, I. (2006). Coping with relationship stressors: The impact of different working models of attachment and links to adaptation. Journal of Youth and Adolescence, 35(1), 24-38. doi:10.1007/s10964-005-9015-4

Shantz, C. U. (1987). Conflicts between children. Child Development 58(2), 283-305. doi: $10.2307 / 113507$

Shi, L. (2003). The association between adult attachment styles and conflict resolution in romantic relationships. American Journal of Family Therapy, 31(3), 143-157. doi: $10.1080 / 01926180301120$

Simon, E.P., \& Baxter, L.A. (1993). Attachment-style differences in relationship maintenance strategies. Western Journal of Communication, 57(4), 416-430. doi: 10.1080/1057031909374465Tillmann-Healy, L.M. (2003). Friendship as method. Qualitative Inquiry, 9(5), 729-749. doi: 10.1177/1077800403254894 
Taylor, P. J., Rietzschel, J., Danquah, A., \& Berry, K. (2015). The role of attachment style, attachment to therapist, and working alliance in response to psychological therapy. Psychology and Psychotherapy: Theory, Research and Practice, 88(3), 240-253. https://doi-org.libproxy.lib.ilstu.edu/10.1111/papt.12045

Tillmann-Healy, L.M. (2003). Friendship as method. Qualitative Inquiry, 9(5), 729-749. doi: $10.1177 / 1077800403254894$

Tokuno, K.A. (1983). Friendship and transition in early adulthood. The Journal of Genetic Psychology, 143(2), 207-216. doi:10.1080/00221325.1983.10533554

Weider-Hatfield, D. (1988). Assessing the Rahim Organizational Conflict Inventory-II (ROCIII). Management Communication Quarterly,1(3), 350-366. doi: $10.1177 / 0893318988001003005$ 